\title{
UMA ERA COM PRAZO DE VALIDADE: A SOCIEDADE DE CONSUMO NO SÉCULO XXI E OS POSSÍVEIS INSTRUMENTOS DE RESTRIÇÃO DA OBSOLESCÊNCIA PROGRAMADA
}

\author{
Lucas Dalmora Bonissoni* \\ Rogerio da Silva**
}

\begin{abstract}
RESUMO: O presente artigo visa analisar a sociedade de consumo a partir de instrumentos de controle da prática da obsolescência programada. Atualmente, produtos são tratados como meros objetos de desejo instantâneo, que rapidamente são descartados ou programados, na medida em que há uma limitação da duração de vida útil do produto. Como forma de frear esses impactos, desponta a necessidade da criação de uma regulamentação específica e a urgência de investimentos em educação e políticas públicas, para proteger o consumidor e educá-lo para um consumo responsável. A metodologia utilizada baseou-se no método dedutivo, adotando-se como técnica a pesquisa bibliográfica.
\end{abstract}

PALAVRAS-CHAVES: Sociedade de Consumo; Hiperconsumismo; Obsolescência Programada; Legislação; Educação.

\section{A VALIDITY ERA: THE CONSUMER SOCIETY IN THE 21ST CENTURY AND THE POSSIBLE PROGRAMMED OBSOLESCENCE RESTRICTION INSTRUMENTS}

\begin{abstract}
The purpose of this article is to analyze the consumer society using tools to control the practice of programmed obsolescence. Currently, products are treated as mere objects of instant desire, which are quickly discarded or programmed, insofar as there is a limitation on the life of the product. As a way of curbing these impacts, the need to create a specific regulation and the urgency of investments in education and public policies, to protect the consumer and educate him for responsible consumption, is highlighted. The methodology used was based on the deductive method, adopting as a technique the bibliographic research.
\end{abstract}

KEYWORDS: Consumer Society; Hyperconsumption; Scheduled Obsolescence; Legislation; Education.

\footnotetext{
"Mestrando em Direito na Universidade de Passo Fundo - UPF, bolsista do Programa de Pós Graduação em Direito, vinculado à linha de pesquisas Relações Sociais e Dimensões do poder, e-mail: lucasdbonissoni@icloud.com

*** Vice-Reitor de Extensão e Assuntos Comunitários da Universidade de Passo Fundo - UPF, Mestre e Doutor em Direito pela Universidade de Santa Cruz do Sul - UNISC, Professor do Programa de Pós-Graduação em Direito pela Universidade de Passo Fundo, e-mail: rogerio@upf.br
}

Rev. de Direito, Globalização e Responsabilidade nas Relações de Consumo | e-ISSN: 2526-0030 | Porto Alegre | v. 4 | n. 2 | p. $108-128$ | Jul/Dez. 2018 


\section{INTRODUÇÃO}

O presente artigo versa sobre as características da sociedade de consumo, marcada por um exibicionismo exacerbado que perpassa a falsa sensação de rotular um personagem que se sobrepõem à outros apenas pelo fato de utilizar símbolos de grandes marcas perante à sociedade. As transformações ocorridas na sociedade contemporânea fez emergir uma verdadeira "era do hiperconsumismo" que reflete o desejo de comprar novos objetos como forma de gozo pleno de felicidade. Nessa fase, utiliza-se produtos para fomentar desejos físicos, sexuais e até sentimentais, uma vez que a emergência desse modo de consumir tem a intenção de materializar o amor em novas mercadorias.

Essa maneira irresponsável de consumo tem como intenção fidelizar clientes e criar um ciclos viciosos para que os consumidores sempre comprem todas as novidades lançadas no mercado. Porém, essa prática acarreta em uma série de fatores prejudiciais à saúde e a qualidade de vida sustentável, tendo em vista que os consumidores tornam-se reféns desse modelo hiperconsumista, e é por conta dessas razões que a temática desse estudo foi problematizada para ser investigada.

Dessa forma, o objetivo geral da presente pesquisa consiste em analisar a sociedade de consumo no século XXI a partir de possíveis instrumentos de controle da prática da obsolescência programada. Especificamente, tem-se a tarefa de compreender a sociedade de consumo até o hiperconsumismo; estudar os impactos da obsolescência programada na sociedade contemporânea e, por fim, investigar como a prática da obsolescência programada pode ser ilidida a partir de instrumentos de controle, como a educação e a legislação.

O discurso da sociedade de consumo e da obsolescência programada se mostra relevante pela sua complexidade e contemporaneidade, porque enfrenta situações que estão em curso no mundo da vida. A contemporaneidade se expressa pela atuação, por exemplo, das corporações transnacionais, que fabricam grande parte de seus produtos com uma previsão de duração de vida útil do objeto. Essa prática gera enormes danos colaterais para a sociedade, além de direcionar toneladas de produtos inutilizáveis por conta de seus defeitos planejados, diretamente para o lixo.

A pesquisa estrutura-se em três tópicos, de modo que no primeiro, a atenção se dedica para o estudo da sociedade de consumo ao hiperconsumismo. Em seguida, passa-se a análise dos impactos da obsolescência programada na sociedade complexa do século XXI e, por fim, o 
estudo se direciona para os instrumentos de controle para inibir a prática da obsolescência programada.

A metodologia utilizada baseou-se no método dedutivo, adotando-se a pesquisa qualitativa e, como técnica de pesquisa, utilizou-se a técnica de pesquisa bibliográfica.

\section{DA SOCIEDADE DE CONSUMO AO HIPERCONSUMISMO}

Com o decorrer dos anos, uma nova concepção de sociedade passou a emergir. Marcada pelas transformações ocasionadas pelo advento da globalização, significativas alterações se verificaram nos planos políticos, econômicos e sociais (BEDIN, 1999, p. 123). Os impactos da globalização conduzem ao "aumento do volume e da velocidade de transmissão de informações, que, com o desenvolvimento tecnológico, perpassam, fortalecem e redefinem a expansão do modo de produção capitalista" (OLSSON, 2003, p. 89-90).

Esses acontecimentos globais provocaram mudanças expressivas no mundo, em especial a progressão do desenvolvimento tecnológico, meios de comunicação, transporte e informática (DOWBOR, 2002, p. 29). Sob essa ótica despontaram importantes mudanças na sociedade, entre elas à "iminência da dissolução dos vínculos sociais devido ao apelo extremado ao consumo e aos efeitos devastadores da lógica perversa do capitalismo real de livre mercado" (BEDIN, 1999, p. 124).

Esse quadro desafiante desponta, segundo Ulrich Beck, a "sociedade de risco" como uma consequência do modelo contemporâneo globalizante e do sistema capitalista de produção e consumo, voltado para alavancar grandes receitas para as corporações transnacionais, ocasionando na individualização da vida privada apresentando significativa "dependência do mercado em todas as dimensões da conduta na vida [...] promovido por meio de comunicação de massa e absorvidos por opiniões, hábitos, gostos e estilos de vida predeterminados” (2011, p. 195). Diante dessas circunstâncias, surge a "sociedade de consumo" marcada pela forma individualista pensar e de se comportar da população, isto é "representa o tipo de sociedade que promove, encoraja ou reforça a escolha de um estilo de vida e uma estratégia existencial consumista, e rejeita todas as opção culturais alternativas" (BAUMAN, 2008, p. 70).

Nesse sentido, a sociedade de consumo, pode ser definida diante de duas passagens ocasionadas pela globalização: a) Advento do capitalismo que aqueceu a economia de consumo e produção em massa de produtos; b) substituição de uma sociedade "rigorístico-disciplinar" 
por uma sociedade "da moda", reestruturada pelas grandes indústrias à consumir produtos ofertados como se fossem um "sonho jubiloso". Desta forma, a sociedade de consumo surge como, "uma cultura hedonista e psicologista que incita a satisfação imediata das necessidades, estimula a urgência dos prazeres, enaltece o florescimento pessoal, coloca no pedestal o paraíso do bem-estar, do conforto e do lazer" (LIPOVESTSKY, 2011, p. 60-61).

A sociedade de consumo é conduzida pelo marketing e designer de novas ofertas e produtos, que criam hábitos ao consumidor por meio de uma "apoteose" publicitária (BAUMAN, 2010, p. 70). Com a vinculação dos aspectos de divulgação comercial, seja por anúncios de televisão, internet ou rádio que "se manifesta de diversos meios, implícitos e explícitos, tornando a vida do cidadão manipulada para o consumo" (PEREIRA; PEREIRA; PEREIRA, 2009, p. 13).

Sucessivamente, as pessoas acabam consumindo para satisfazer suas futilidades, apenas para adquirir o produto da moda do mercado, e, esquecem de atender suas necessidades pessoais, uma vez que a sociedade de consumo é voltada para "as novas elites do mundo econômico alardeiam sem complexos seus gostos pelos produtos de luxo e pelos símbolos de posição social. [...] O esnobismo, o desejo de parecer rico, o gosto de brilhar, a busca pela distinção social” (LIPOVESTSKY, 2008, p. 51).

Esse desejo de parecer rico e buscar novos produtos para ostentar seu ego pessoal perante a sociedade, aquece o mercado a se manter sempre com novidades, inserindo no imaginário cultural "tendências de estilo" para o consumidor, e, indiretamente eleva a distinção social, ao considerar que para participar de determinados grupos, deve utilizar emblemas da moda e dirigir carros importados "como certeza de reconhecimento, aprovação e inclusão" (BAUMAN, 2008, p. 108). Nesse sentido, a utilização de produtos patrocinados por grandes marcas desponta a ideia de que "aquele que pode consumir mais e melhores produtos detém o poder social e econômico sobre os outros" (PEREIRA; CALGARO; PEREIRA, 2016, p. 40).

Como consequência dessas atitudes, as pessoas deixam de "reconhecer" os interesses coletivos, uma que vez que cria-se uma perspectiva concretamente individualista e egocêntrica, com hábitos de consumo considerados desnecessários, exatamente como ocorre em nossa sociedade (HABERMAS, 1989). Além disso, a falta de solidariedade humana, acompanhada com a escassez o exercício de uma cidadania ativa, provocam diretamente prejuízos aos bens da coletividade, e "tudo isso contribuí para o aniquilamento dos espaços públicos, que passam a ser ocupados pelos domínios do mercado" (BODNAR, 2012, p. 45). 
O desejo do reconhecimento pessoal para ser "alguém mais" perante a sociedade, escancara os problemas da sociedade de consumo, "dividido entre as coisas a serem escolhidas e os que as escolhem; as mercadorias e seus consumidores: as coisas a serem consumidas e os seres humanos que as consomem" (BAUMAN, 2008, p. 20). Como resultado, o sujeito acaba tornando-se a própria mercadoria desejável diante de sua comunidade, uma vez que será lembrado pelo o que veste, e não por aquilo que produziu em vida em prol de benefícios coletivos, ou seja, "a produção de bens de consumo é agora um fenômeno cultural: compra-se o produto tanto por sua imagem quanto por sua identidade imediata" (JAMESON, 1996, p. 138). Portanto, o homem não está mais preocupado em sobreviver, mas, sim, “consumir para poder viver ou se o homem vive para poder consumir" (BAUMAN, 1999, p. 88).

Desta forma, a lógica da sociedade de consumo se reflete na forma irresponsável da sociedade contemporânea, uma vez que, diante da insatisfação perpétua dos consumidores em buscar nos produtos para elevar seu ego, a desvalorização e a depreciação dos objetos perdem seu sentido após a sua aquisição, necessitando procurar novos itens no mercado para satisfazer suas necessidades. Nesse sentido, a demanda pelo consumo nunca se esgotará, porque o ciclo vicioso dos produtos leva ao excesso e extravagância de mercadorias e de novos desejos, uma vez que é pelo consumo que o homem encontra o caminho para a felicidade. (BAUMAN, 2008, p. 195).

Isto posto, nota-se que a sociedade de consumo é marcada pelo consumismo individualista e exagerado dos seres humanos. Porém, atualmente, a sociedade está cruzando por novas transformações, e um outro modo de consumir emerge na sociedade contemporânea, passamos para uma "era do Hiperconsumismo", que cada vez mais, induz a população à buscar produtos que fomentam os desejos relacionados a sua aparência física, sentimental, carnal, relacional, ou seja alegria em abundância para o gozo pleno da felicidade (LIPOVESTSKY, 2007, p. 42).

Ao contrário do que aparenta na sociedade consumista, a era do Hiperconsumismo traz uma nova concepção de consumo tendo em vista que, o anseio da população não está mais voltado para o exibicionismo perante a sociedade, porque atualmente a sociedade do hiperconsumo não está preocupada em utilizar bens de consumo para aparentar uma diferença de condição social, em razão de que "os objetos significavam um sinal de status, porém agora eles são colocados à disposição do indivíduo; digamos, nessa fase os bens de consumo não são procurados como método de diferenciar do outro" (RODRIGUES; PEREIRA; CALGARO, 
2016, p. 100). No mesmo sentido, Lipovestsky (2007, p. 37) acrescenta que "o apogeu do consumo já não tem a ver com o signo diferencial, mas com o valor experimental, o consumo 'puro' que funciona não como significante social, mas como panóplia de serviços destinados ao indivíduo".

Dessa forma, o hiperconsumismo visa atender a busca insana pela felicidade, considerando que as inovações do mercado são desejadas pelo homem para propiciar e estimular sua satisfação própria. Porém, cada vez mais surgem novos movimentos sociais, que se difundem universalmente devido aos efeitos da "moda", e, consequentemente, dias depois, as tendências antigas acabam "falecendo" por conta da velocidade de opiniões e novos fatores, afinal as pessoas creem e descreem facilmente, "tudo torna-se mais ligeiro, por exemplo: a elaboração da ideia, a popularização do mesmo e depois seu decréscimo" (RODRIGUES; PEREIRA; CALGARO, 2016, p. 101).

Por conta disso, em razão da velocidade de consumo e dos impactos globalizantes, a troca de bens e o ritmo de produção de novidades está cada vez mais frenético, enraizando gradativamente essa cultura de hiperconsumo, "incorporado perfeitamente pela sociedade em seu modo de vida, em que as roupas, os gostos musicais e até as religiões são consumidos, destruídos e descartados em um ritmo cada vez maior" (LIPOVESTSKY, 2007, p. 67). Com o evento desse fenômeno nota-se que o estilo de vida da sociedade e os avanços tecnológicos aquecem o mercado, porém, liga-se um alerta de que "vivemos o tempo dos objetos: quero dizer que existimos segundo o seu ritmo e em conformidade com sua sucessão permanente. Atualmente somos nós que os vemos nascer, produzir-se e morrer" (BAUDRILLARD, 2007, p. 15).

Completa Lipovestsky que "chegamos ao momento em que a comercialização dos modos de vida não mais encontra resistência estruturais, culturais e nem ideológicas; e em que as esferas da vida social e individual se reorganizam em função da lógica do consumo" (2011, p. 31). Portanto, nessa era hiperconsumista emerge, "a materialização do amor nas coisas", posto que os homens trabalham de mês à mês para receber seu salário e gastar com objetos para satisfazer seus interesses particulares e de sua família, porque "estando fora de casa por tantas horas, compensam sua ausência com presentes que custam dinheiro. Materializam o amor. E assim continua o ciclo" (HOCHSCHILD, 2003, p. 108).

Por esses motivos, o sujeito hiperconsumista apenas se sentirá completo quando comprar todos os objetos que saciam suas necessidades, conforme descreve Cambell e Barbosa 
(2007, p. 53) "eu compro a fim de descobrir quem sou”. Portanto, prevalece uma manipulação de condutas que controlam a intensidade e a gana do ser humano, que se transforma em uma "máquina de consumo [...] e que troque a sua condição de cidadão pela condição de consumidor" (CALGARO; PEREIRA, 2016, p. 61). Desta forma, emerge a figura do sujeito na sociedade consumocentrista, "não é somente adestrado a consumir e a fazer com que o consumo seja o centro de suas atenções mas, também, que se conforme com a posição de vigiados pelos diversos instrumentos que o consumo cria" (CALGARO; PEREIRA, 2016, p. 62).

O hiperconsumo promete uma passagem fácil para a felicidade, fazendo os seres humanos reféns do próprio destino, ou melhor, do próprio consumo, tendo em vista que, atualmente o amor existe para adquirir novos objetos e não mais para as relações pessoais, uma vez que "hoje, amar é como um passeio no shopping, visto que, tal como outros bens de consumo, o relacionamento humano deve ser consumido instantaneamente, não requer maiores intimidades nem grandes conhecimentos sobre a pessoa a se relacionar" (PEREIRA, PEREIRA, PEREIRA, 2009, p. 15). Por fim, Jürgen Habermas (2000, p. 137-138), denomina o tema como "o nascimento da tragédia", em que a crueldade profunda e a dor, são consideradas como "o prazer, projeções de um espírito criador, sem escrúpulos se entrega ao gozo despreocupado do poder e da arbitrariedade de suas criações fictícias".

\section{OS IMPACTOS DA OBSCELESCÊNCIA PROGRAMADA NA SOCIEDADE COMPLEXA DO SÉCULO XXI}

Para aumentar o rendimento da produção de seus bens, as grandes empresas estipulam a duração da vida útil de seus produtos como uma forma de manter sempre uma clientela fidelizada de consumidores. Dessa forma, emerge a figura da obsolescência programa, que diretamente gera efeitos colaterais para a sociedade, principalmente por direcionar toneladas de produtos defasados e inutilizáveis para o lixo.

Sobre o tema obsolescência, existem três hipóteses que tornam os materiais obsoletos: a) pela função: o produto recém lançado com advento tecnológico, executa funções melhores que o existente no mercado; b) pela qualidade: quando o produto fabricado já contempla uma durabilidade prevista pelas empresas, manufaturado de uma forma mais frágil para que tenha uma duração de vida útil pré-estipulada; c) pelo desejo: quando o antigo produto, mesmo 
funcionando em perfeitas condições, perde o interesse do consumidor, em razão da publicidade lançada em novos itens, apenas alterando seu designers, deixando-o mais estilosos e atuais do que o anterior. (PACKARD, 1965, p. 24)

O objeto do presente artigo é estudar os impactos da obsolescência de qualidade, também conhecida como programada ou planejada, que "trata de um artifício que reduz a durabilidade dos produtos ou o ciclo de vida de seus componentes, forçando o consumidor a uma recompra prematura [...] o que incrementa o lucro empresarial e impacta o meio ambiente" (MIRAGEM, 2013, p. 325). Desta forma, obsolescência pode ser definida como "a ação humana de planejar e determinar o que se tornará obsoleto e ultrapassado, sem que a coisa tenha em essência deixado de ser ou existir" (PACKARD, 1965, p. 22).

Os produtos obsoletos nascem com características próprias, porque que as grandes empresas visando lucro com os rendimentos da sociedade hiperconsumista, utilizam materiais com uma longevidade definida para quebrarem ou pararem de funcionar com o passar dos anos, uma vez que a falta de qualidade dos serviços prestados em cada produto, tornam-nos frágeis para incentivar os clientes a trocarem por novos bens. (RUIZ MALBAREZ; ROMERO GONZÁLEZ, 2011).

Por mais atual que seja, a obsolescência programada foi uma estratégia mercantil criada no ano de 1932, de acordo com publicação do artigo "Ending the Depression Through Planned Obsolescence" de Bernard London, com a intenção de incentivar um consumo forçado para a população devido à crise empresarial, uma vez que as pessoas consumiam menos do que a produção das fábricas, e por esse motivo foi desenvolvido a obsolescência programada, para estimular o consumismo e fomentar o mercado da época (LEONARD, 2011, p. 23).

Consequentemente, essa prática obsoleta não deixou de existir, pelo contrário, foi aprimorada pelas grandes empresas com o passar dos anos, para alcançar resultados que limitam a validade dos produtos, "hoje o que se produz não se fabrica em função do respectivo valor de uso ou da possível duração, mas antes em função da sua morte, cuja a aceleração só é igualada pela inflação de preços" (BAUDRILLARD, 2007, p. 42).

A momentânea durabilidade dos bens estão relacionados à uma estratégia de marketing, visando aumentar o lucro das grandes empresas, uma vez que a apoteose de novas ofertas e a difamação das antigas, aumenta a "taxa de desperdício, e pela decrescente distância temporal entre o brotar e o murchar do desejo, que o fetichismo da subjetividade se mantém vivo e digno de crédito, apesar da interminável série de desapontamentos que ele causa" 
(BAUMAN, 2008, p. 31). Completa, Lemos (2014, p. 26), que "não se pode esquecer que o consumo, além da satisfação das necessidades físicas e sociais, envolve aspectos subjetivos, ligados aos desejos pessoais. Aliás, esse é o apelo mais utilizado pelo marketing para fins de oferecimento de produtos e serviços para o consumo". Dessa forma, para Lipovestsky (2004, p. 60-61), os produtos obsoletos criados pelas grandes empresas possuem variedades em todas as áreas, sejam dos esportes ao passatempo, da beleza à alimentação, da higiene a educação, sempre estipulando a sedução, com novidades supérfluas para iludir o universo do consumo onde o sistema da moda é o modelo a ser seguido, sempre com o intuito de garantir o mercado futuro, para que os novas mercadorias sejam vendidas e as velhas percam sua função.

Portanto, o eterno modo de consumo presente em nossa sociedade provoca sérios riscos futuros, devido ao excesso dos antigos objetos que se tornam obsoletes, gerados pela prática proposital das grandes empresas que visam apenas o lucro, e, também, essa responsabilidade deve ser imposta ao próprio ser humano que deixa de pensar no próximo apenas para comprar produtos com a única intenção de satisfazer os seus fetiches, deixando de pensar que essas atitudes ameaçam a preservação do planeta. Porque, o acúmulo desproporcional de lixo, é aumentado significativamente ano após ano, uma vez que a composição dos resíduos prejudicam o meio ambiente e a qualidade de vida da população, principalmente nas áreas periféricas das cidades, onde se localizam os grandes lixões (MAGERA, 2012).

Sob essa ótica, os efeitos do hiperconsumismo geram uma insegurança para toda a sociedade, que contribuem tanto para a degradação do meio ambiente, como causam vícios de consumo insanáveis para muitas pessoas, provocando doenças graves como depressão e síndromes do pânico, uma vez que os novos riscos "não estão vinculados ao lugar em que foram gerados - a fábrica. De acordo com seu feitio, eles ameaçam a vida do planeta, sob todas as suas formas" (BECK, 2011, p. 43).

Latouche (2009), alerta a sociedade no sentindo que, o crescimento econômico das grandes empresas pela produção de novidades, confronta diretamente um sistema de desenvolvimento sustentável, em que a capacidade de regeneração da Terra não acompanha a alta escala de fabricação de mercadorias, posto que o homem transforma produtos em resíduos mais rápido que a própria recomposição da natureza.

Porém, a questão da obsolescência programada gira em torno de uma grande dúvida, quanto tempo as coisas devem durar? Se pensarmos no mercado automobilístico, o mundo conta 
com 1,3 bilhões de veículos, e segundo pesquisas, no ano de 2050, esses números ultrapassarão 2 bilhões, trazendo consequências diretas para a saúde e para o meio ambiente (ONU, 2015). Em média um veículo tem uma duração que não ultrapassa a casa dos sete anos, e apesar da pouca preocupação do Estado para fiscalizar a atitude das empresas automobilísticas, a comprovação do fato da existência da obsolescência programada é muito difícil, porque depende de prova pericial e de uma série de requisitos para sua caracterização.

Esse tema já foi assunto no Superior Tribunal de Justiça (REsp 984.106), em que foi contestada os defeitos de uma máquina agrícola, afirmando que não decorria de desgaste natural ou mau uso, mas que era um defeito de projeto proposital, tratando-se de vício oculto. $\mathrm{Na}$ decisão, o Ministro reconheceu que, se tratando de vício oculto devido a problemas da própria fabricação, o prazo para reclamar pela reparação se inicia no momento em que ficar evidenciado o defeito, mesmo que a garantia já tenha terminado, devendo ter-se sempre em vista o critério da vida útil do bem. E, ainda, apresentou propostas para reformar o Código de Defesa do Consumidor Brasileiro, que será aprofundada no próximo item (STJ, 2012).

No mesmo sentido os produtos eletrônicos também apresentam problemas projetados. Recentemente, o vice-presidente de marketing empresa Apple, Greg Joswiak, em entrevista ao podcast "The Talk Show", disse que a obsolescência programada é "a coisa mais louca do mundo eu the dar uma experiência porca para que volte a comprar nosso novo produto", alegando que "as pessoas se esqueceram de tantos pontos positivos das atualizações de softwares. Para começar, temos um índice de $95 \%$ de satisfação do consumidor com o iOS 11 , é incrível" (TECHMUNDO, 2018). Entretanto, a empresa é acusada de planejar seus smartphones para que fiquem mais lentos e, consequentemente a carga das baterias dure menos a cada atualização, inclusive, sendo alvo de diversas demandas judiciais nos Estados Unidos, com valores astronômicos, por conta da suposta prática de programação obsoleta existente em seus produtos (BUSINESS INSIDER, 2017). Não por menos que a empresa foi citada no Parecer do Comité Econômico e Social Europeu, devido ao desperdício de recursos e a emissão de poluentes são tais que a sociedade civil, e muitos representantes eleitos não complacentes com essas práticas organizam-se para salientar e combater as incoerências do sistema (ações coletivas nos Estados Unidos contra a Apple, queixa apresentada no Brasil, projetos de lei em Bélgica e na França no início de 2013) (UER-LEX, 2014).

Por óbvio, independente da comprovação de culpa ou não das grandes empresas, os sinais do hiperconsumismo são notórios, visto que a produção em massa dos equipamentos 
eletrônicos são os que mais agridem o meio ambiente, uma vez que o volume de celulares no mundo, segundo a ONU, é de 3 bilhões de aparelhos, e apenas 15\% são reciclados, e a outra parte é destinada para os lixões. Os "e-lixos" como são conhecidos, oferecem perigo à saúde humana devido a sua composição baseada em cobre, ouro, chumbo, níquel, zinco, berílio, tântalo, arsênico, mercúrio e outros. E, “todos esses materiais são usados na produção, e depois, quando o produto fica obsoleto, tudo vai parar nos lixões. Tudo o que compôs esses objetivos e contribuiu para uma criação industrial, vai permanecer no ar, na terra e na água durante anos, até séculos!” (MAGERA, 2012, p. 107).

Como resultado do impacto da obsolescência programada, os produtos que se tornam defasados aos olhos do consumidor, a cada ano, varia entre 5 e 7 milhões de toneladas de eletrônicos que se tornam obsoletos. Além disso, seus componentes tóxicos contaminam a terra, o ar, a água e todos os habitantes do planeta e, ainda, ao invés de utilizar a tecnologia em prol do meio ambiente, acontece o oposto, uma vez que $85 \%$ dos e-lixos vão diretamente para aterros sanitários e incineradores (LEONARD, 2011).

Logo, o resultado desse ciclo vicioso acarreta em grandes prejuízos para a sociedade, porque a excessiva aquisição de produtos e a velocidade para produzir novos produtos já faz parte do estilo de vida da sociedade moderna, em que roupas de grife, estilos musicais, e até as religiões são consumidos, destruídos e descartados em um ritmo cada vez maior (LIPOVESTSKY, 2007, p. 67). Por conta desses acontecimentos do hiperconsumo, os produtos antigos deixam de ser aproveitados e acabam desvalorizando a sua durabilidade, igualando-o a "velho, defasado e impróprio", diretamente destinado ao lixo (BAUMAN, 2008, p. 31).

Assim, percebe-se que a curta expectativa de vida dos objetos lançados no mercado com uma vida útil reduzida, para que os consumidores tenham que adquirir novos equipamentos num curto espaço de tempo. Esse ciclo vicioso do consumo consiste na obsolescência programada, onde a fragilidade dos bens consumidos pela sociedade constantemente aumenta a taxa de desperdício de antigas mercadorias, assinalando "um aumento espetacular na indústria de remoção do lixo". Consequentemente, os componentes tóxicos dos produtos descartados contaminam nosso meio ambiente prejudicando todos os seres humanos (BAUMAN, 2008, p. 44-45).

Estudado, portanto, a prática da obsolescência programada, passa-se a analisar os possíveis instrumentos de controle para ilidir essa prática. 


\section{A EDUCAÇÃO E A LEGISLAÇÃO COMO INTRUMENTOS DE CONTROLE DA OBSOLESCÊNCIA PROGRAMADA}

As tecnologias advindas da globalização e as novidades do mercado não param de revolucionar as mudanças no planeta. Porém, como consequência, emerge em nossa sociedade o desejo de consumidor cada vez mais para benefícios próprios, onde as pessoas estão dispostas a pagar mais caro apenas para saciar o seu próprio ego, "deixando que valores e respeito para com o outro e com o meio ambiente sejam deixados de lado" (CALGARO, PEREIRA, 2016, p. 66).

Ocorre que, nem todas as classes tem condições de adquirir os produtos da moda oferecidos pelo mercado, e, esses fatores consumeristas impactam diretamente nas pessoas que não tem recursos financeiras de comprar tais objetos, ocasionado um "sentimento de ser rejeitado, excluído e abandonado, e em última instância se reflete na dor da inadequação social" (BAUMAN, 2008, p. 109).

Por conta disso, a geração hiperconsumista acelera a fabricação de novos produtos obsoletos para que o mercado nunca deixe de ser aquecido, caminhando na contramão de uma produção bens responsáveis e comprometidos não só com o meio ambiente, mas também de bens responsáveis.

O pensamento egocêntrico deteriora os conceitos de uma sociedade coletiva, em que pensar no próximo, ou então, em benefício da coletividade, não estão mais em pauta. A modernidade nos ensina a cada vez mais pensar individualmente, motivando a população a competir uma com as outras, com reflexos que nos movem para um "Estado de urgência", onde "disseca a estratégia de um sentimento de urgência intenso e cultivado de maneira ampla, fornecem tanto a indivíduos como a instituições um alívio ilusório" prendendo consumidores a onda de consumo (BAUMAN, 2008, p. 121).

A grande dificuldade de combater os resquícios da obsolescência programada, é que estamos em uma sociedade descartável, na qual as corporações transnacionais detêm um poder econômico superior ao Estado, gerando um crescimento lucrativo para novas tecnologias, que, consequentemente, resultam em um decrescimento ambiental ${ }^{1}$. Nesse sentido, cabe a seguinte reflexão: Como pode-se frear esse esquema bilionário que pré-determina o tempo de vida útil

\footnotetext{
${ }^{1}$ A palavra de ordem "decrescimento" tem como principal meta enfatizar fortemente o abandono do objetivo do crescimento ilimitado, objetivo cujo motor não é outro senão a busca do lucro por parte dos detentores do capital, como consequências desastrosas para o meio ambiente e portanto para a humanidade (LATOUCHE, 2009, p. 4)
} 
de cada produto fabricado? Como resposta, o presente estudo visa apresentar duas propostas, uma por meio da Legislação, já aplicada em alguns países da Europa, e outra com base na Educação por meio informações como meio de humanizar as relações de consumo.

Para prevenir os abusos das corporações transnacionais, a Europa quer acabar com a obsolescência programa, e começou a tratar o tema como uma de suas prioridades (FROTA, 2017). A União Europeia publicou diversas recomendações, por meio do Comité Econômico e Social Europeu (CESE), sobre o tema: "Por um consumo mais sustentável: O ciclo de vida dos produtos industriais e informação do consumidor a bem de uma confiança restabelecida". Entre as principais recomendações apresentadas pelo Parlamento Europeu, é realizar uma distinção clara entre defeituosidade intencional e aceleração dos novos padrões de consumo. "O CESE preconiza a proibição total dos produtos cuja defeituosidade seja programada para provocar o fim da vida do aparelho. Estes casos, raros mas flagrantes, [..] apenas alimentam a desconfiança dos cidadãos em relação às empresas" (UER-LEX, 2014).

Além dessa difícil missão, o CESE recomenda que as empresas facilitem a reparação dos produtos defeituosos, da seguinte maneira, apresentando três propostas para os fabricantes: "tornar a reparação tecnicamente possível; dar aos consumidores a possibilidade de adquirir peças sobressalentes até cinco anos após a aquisição; a compra do produto deve ser acompanhada de informação sobre as possibilidades de reparação e a forma de as utilizar" (UER-LEX, 2014). Nesse sentido, o Comité propõem um novo sistema de garantias, direcionado através de uma duração mínima de funcionamento, ficando as reparações à cargo do produtor, considerando-se que o consumidor é que tem que suportar os custos de cada reparação e da redução da vida útil dos produtos.

Já no Brasil, o Código de Defesa do Consumidor, em seu art. 4, II, inciso "d”, prevê a ação governamental no sentido de proteção ao consumidor, "pela garantia dos produtos e serviços com padrões adequados de qualidade, segurança, durabilidade, e desempenho" (BRASIL, 1990). O art. 26, $\S 3^{\circ}$, do mesmo diploma legal, garante que se tratando de vícios ocultos, o prazo de decadencial inicia-se no momento em que ficar comprovado o defeito (BRASIL, 1990). Porém, é esse o ponto cego de nossa legislação, comprovar o defeito oculto de fabricação, uma vez que passado o prazo da garantia as empresas não costumam realizar reparação, e ainda, alegam que muitas vezes não existem mais peças para solucionar o problema em questão, cabendo ingressar ao judiciário para buscar sua tutela (TJRJ, 2011). Dessa forma, o Ministro Salomão apresenta propostas para reformar o Código de Defesa do Consumidor, 
muitas com base do projeto elaborado pela União Europeia, entre elas a inclusão de dispositivos que preveja a abusividade da obsolescência programa, para que os fornecedores indiquem a vida útil de cada produto, ou a quantidade de utilização prevista, além de uma regulamentação expressa para aplicar multas administrativas as empresas que comprovadamente praticarem os abusos da obsolescência programa (STJ, 2012).

No mesmo sentido, como proposta de prevenção de práticas obsoletas a ONU por meio da Agenda 2030, elencado no seu objetivo " $n .{ }^{\circ}$ 12" sobre o "Consumo e Produção Responsáveis", aplica a ideia de assegurar padrões de produção e de consumo sustentáveis, para reduzir substancialmente a geração de resíduos por meio de prevenção, redução e reuso (ONU, 2018). Deste modo, um dos caminhos apresentados pela organização intergovernamental para proteger os consumidores é a reutilização dos produtos que não tem mais utilidades, com a intenção de criar novas tecnologias para o bem da humanidade, para desenvolver novas maneiras de reciclar os objetos que venham a se tornar obsoletos com o passar dos anos.

Porém, nos últimos anos, tem-se mostrado insuficiente apenas a existência de legislações para recomendar ou até mesmo punir empresas, cada vez mais emerge em nossa sociedade a necessidade de políticas públicas para combater a obsolescência programada e, também, a desigualdade social, "por isso, as políticas ambientais não podem ser vistas como obstáculos para o crescimento-econômico brasileiro, mas sim complementares ao verdadeiro desenvolvimento do país" (FACHINELLI, STEINMETZ. 2016, p. 122).

Dessa forma, a União Europeia em suas recomendações, também prevê a importância da Educação e a sensibilização dos consumidores para a utilização adequada e sustentável dos produtos. "O CESE recomenda que os Estados-Membros encorajem o consumo responsável, sobretudo na fase da educação, a fim de que os consumidores tenham em conta o impacto no ambiente do ponto de vista do ciclo de vida do produto, a pegada ecológica e a qualidade dos produtos" (UER-LEX, 2014).

Na sequência, a outra alternativa de frear os impactos da obsolescência programa é com base nas propostas de Educação e informação como meio de humanizar as relações de consumo. Em que pese os direitos do consumidor do ponto de vista legislativo estejam consolidados no Brasil e na Europa, não tem sido suficientes para combater a obsolescência programada. Além da legislação é necessário trabalhar a educação e a conscientização dos consumidores e fornecedores. O consumidor precisar ser educado para exigir produtos de qualidade que não comprometam o ambiente. Os direitos dos consumidores tem despertado o 
interesse não só no Brasil, mas também na Europa, e reforça-se a ideia de que cada vez mais é preciso conscientizar o cidadão sobe o consumo, uma vez que de nada adianta existirem regulamentações se o próprio ser humano continuar a consumir como se não houvesse amanhã.

A Constituição Federal do Brasil assegura direitos fundamentais aos cidadãos, e em seu art. $5^{\circ}$, inciso XXXII, afirma que o Estado promoverá a defesa do consumidor, além disso, $\mathrm{o}$ art. 225, garante que todos têm direito ao meio ambiente ecologicamente equilibrado, impondo-se ao Poder Público e à coletividade o dever de defendê-lo e preservá-lo para as presentes e futuras gerações (BRASIL, 1988). Recentemente, foi alterada a Lei Federal $n^{\circ}$ 12.305/2010 que instituiu a Política Nacional de Resíduos Sólidos, que dispõe princípios, objetivos e instrumentos sobre a gestão de resíduos sólidos, apresentando "padrões sustentáveis de produção e consumo: produção e consumo de bens e serviços de forma a atender as necessidades das atuais gerações e permitir melhores condições de vida, sem comprometer a qualidade ambiental e o atendimento das necessidades das gerações futuras (BRASIL, 2010)

É dever do Estado fiscalizar e transmitir que as informações sejam corretamente passadas aos consumidores, alertando sobre os problemas gerados por um consumo inconsciente, egoísta e manipulador. A Educação necessita ser um instrumento primordial para apresentar novas reflexões sobre os direitos dos consumidores e dos seus deveres como cidadãos. "O consumidor deve ser educado quanto ao seu próprio poder perante os produtores e prestadores de serviços para equiparar-se a estes em seu relacionamento" (SILVA, 2011, p. 99).

Além da educação, a criação e o investimento em políticas públicas pode ser um caminho para atingir resultados em benefício de todas as classes sociais, desde que promovam ações paliativas para promover a atuação do Estado em busca das garantias constitucionais e do bem-estar do seu povo. "A expressão políticas públicas designa todas as atuações do Estado, cobrindo todas as formas de intervenção do poder público na vida social” (GRAU, 2000, p. 21).

Dessa forma, o Estado deve fomentar e incorporar em seus programas temáticas sustentáveis para forjar movimentos sociais e a criação de novas políticas públicas. No Brasil, já existem alguns programas direcionados à discutição do impacto do consumo e da sustentabilidade, como o "Caderno de Investigações Científicas - Consumo Sustentável” que apresenta interfaces entre as normas ambientais e a legislação consumerista, sobre os temas de proteção ao consumidor, e política nacional de resíduos sólidos na perspectiva da tutela do consumidor (MINISTÉRIO DA JUSTIÇA, 2013). No Rio Grande do Sul, a Faculdade de 
Direito da Universidade de Passo Fundo, com o auxílio de recursos do Fundo Estadual, criou o Balcão do Consumidor que atua em parceria com a Prefeitura Municipal (PROCON) de cada região e o Ministério Público Estadual, “com o objetivo de realizar diversas atividades de educação para o consumo, que beneficiam cidadãos das mais de 80 cidades [...] com os recursos obtidos, foram elaborados cartilhas, livros, palestras, seminários, desenvolvidos programas de televisão, entre outros” (SILVA, 2016). "Os atendimentos são feitos por alunos da Faculdade de Direito, com a orientação de professores que integram o projeto, e, desde o início de suas atividades, o Balcão do Consumidor já atendeu, somente em Passo Fundo, mais de 90 mil pessoas" (BALCÃO DO CONSUMIDOR UPF, 2018).

Dentre as formas de combater a obsolescência programa ora analisadas (legislação e educação) destaca-se como positiva a atuação do Estado, com a intenção de educar os cidadãos, seja por meio de informações direcionadas em programas governamentais ou por meio de políticas públicas, visando sempre combater esse problema social presente na sociedade de consumo, a fim de reparar os vícios causados à sociedade hiperconsumista. Porém, mais que uma atuação do Estado, para que isso efetivamente aconteça, é necessário que o próprio cidadão exija do ente estatal a criação de políticas públicas que visem inibir a prática da obsolescência programada, cumprindo seu papel de consumidor no Estado Democrático de Direito.

Além disso, a regulamentação de recomendações proposta pela União Europeia, pode ser o caminho para futuras legislações que visem defender os consumidores e o meio ambiente dos produtos destinados a serem destruídos, forçando a industrialização de produtos com alta qualidade e longa duração. Por fim, toda iniciativa que tenha como objetivo a regulamentação que favoreça o cidadãos será importantíssima para garantir uma melhor qualidade de vida para a sociedade e o meio ambiente.

\section{CONCLUSÃO}

Pelo estudo ora proposto, verifica-se que seu debate no mundo contemporâneo se faz necessário diante dos problemas ambientais e sociais que se enfrentam atualmente. A aquisição exagerada de produtos e serviços de forma irresponsável acarreta sérios danos, muitas vezes irreparáveis ao meio ambiente, que podem colocar em risco a existência humana, posto que todos os produtos que se tornam obsoletos irão permanecer no ar, na terra e na água, durante anos e anos. 
Nesse passo, verificou-se que, com o advento de novas tecnologias, o comércio cresce e o meio ambiente arca com as consequências dos impactos gerados pela obsolescência programada, e da falta de sensibilização dos consumidores na hora de reutilizar e cuidar dos seus produtos, uma vez que demonstra-se que humanidade está em direção ao caminho do lixo.

A prática da obsolescência programada tem tomado proporções inimagináveis, além de ter se tornado irrefreável atualmente. Inseridos nessa sociedade do hiperconsumismo, o ser humano tem uma falsa percepção quanto ä durabilidade dos produtos, especialmente pela falta de esclarecimento e regulamentação específica nesse sentido.

Os instrumentos como a legislação e educação constituem formas de frear os impactos da obsolescência programada. Destaca-se que, a União Europeia inovou ao criar um comitê para regulamentar e sugerir formas para que os fabricantes apresentem reparos de seus produtos e garantias estendidas aos consumidores.

De outra forma, seria ineficaz a mera regulamentação pela legislação se a população não se conscientizar do seu papel como cidadão e repensar sua conduta em prol de proteger os bens comuns. Por fim, destaca-se como positiva a atuação do Estado, com a intenção de educar os cidadãos seja por meio de informações direcionadas em programas governamentais, seja por meio de políticas públicas, visando combater um dos grandes problemas a sociedade de consumo, a obsolescência programada e os vícios gerados na sociedade hiperconsumista.

Por fim, o Estado não tem sido eficaz em cumprir com se papel de educar o consumidor para o consumo responsável, de modo que essa tarefa vem sendo desempenhada por outros agentes, como associações, por exemplo. Como solução, aponta-se a necessidade de reivindicações e cobranças pelo próprio cidadão para que cumpra com seu papel constitucional de garantidor da defesa do consumidor. É necessário que a educação do consumidor seja realizada de forma a conscientizar a sociedade, a partir de um trabalho a ser realizado em escolas, associações e nas comunidades em geral, para que seja possível uma transformação dos costumes a longo prazo. 


\section{REFERÊNCIAS}

BALCÃO DO CONSUMIDOR. O balcão. 2018. Disponível em: <https://www.upf.br/balcaodoconsumidor/o-balcao> Acesso em: 04 set. 2018.

BAUDRILLARD, Jean. A sociedade de consumo. Lisboa: Edições 70, 2007.

BAUMAN, Zygmunt. Vida para consumo: a transformação das pessoas em mercadorias. Rio de Janeiro: Editora Zahar, 2008.

Globalização: as consequências humanas. Rio de Janeiro: Editora Zahar, 1999.

BECK, Ulrich. Sociedade de risco: rumo a uma outra modernidade. $2^{\mathrm{a}}$ ed. São Paulo: Editora $34 ; 2011$.

BEDIN, Gilmar Antonio. Estado, cidadania e globalização do mundo: algumas reflexões e possíveis desdobramentos. In: OLIVEIRA, Odete Maria de (Coord.). Relações internacionais e globalização: grandes desafios. 2 ed. Ijuí: Unijuí, 1999. p. 123-150.

BODNAR, Zenildo. O cidadão consumidor e a construção jurídica da sustentabilidade. In: PILAU SOBRINHO, Liton Lanes; SILVA; Rogerio da. Balcão do consumidor: consumo e sustentabilidade. Passo Fundo: Ed. Universidade de Passo Fundo, 2012.

BRASIL. Constituição da República Federativa do Brasil de 1988. Disponível em: <http://www.planalto.gov.br/ccivil_03/constituicao/constituicaocompilado.htm> Acesso em: 04 set. 2018.

Lei $\mathrm{n}^{0}$ 8.078, de 11 de setembro de 1990 (Código de defesa do consumidor). Disponível em: <http://www.planalto.gov.br/ccivil_03/Leis/L8078.htm> Acesso em: 04 set. 2018.

. Lei $\mathbf{n}^{0}$ 12.305, de 02 de agosto de 2010 (PNRS). Disponível em: <http://www.planalto.gov.br/ccivil_03/_Ato2007-2010/2010/Lei/L12305.htm> Acesso em: 04 set. 2018 .

BUSINESS INSIDER. Apple is facing lawsuits over its policy of slowing down older iPhones. 2017. Disponível em: <https://www.businessinsider.com/two-class-action-lawsuitsapple-iphone-throttling-2017-12> Acesso em: 04 set. 2018.

CALGARO, Cleide; PEREIRA, Agostinho Oli Koppe. A sociedade consumocentrista e a disciplina do sujeito na modernidade: uma análise dos impactos socioambientais. In: Carolina Medeiros Bahia, Cleide Calgaro (Org.). Direito, globalização e responsabilidade nas relações de consumo I [Recurso eletrônico on-line] organização CONPEDI/UNICURITIBA.

CAMPBELL, Colin; BARBOSA, Lívia (org). Cultura, consumo e identidade. Rio de Janeiro: FGV, 2007. 
DOWBOR, Ladislau. A reprodução social. Petrópolis: Vozes, 2002.

EUR-LEX. Parecer do Comité Económico e Social Europeu sobre o tema «Por um consumo mais sustentável: $O$ ciclo de vida dos produtos industriais e informação do consumidor a bem de uma confiança restabelecida» (parecer de iniciativa). Disponível em: $<$ https://eur-lex.europa.eu/legal-content/PT/TXT/?uri=CELEX\%3A52013IE1904> Acesso em: 04 set. 2018.

FACHINELLI, Bianca Amoretti; STEINMETZ, Wilson. Normas internacionais e nacionais sobre o meio ambiente no Brasil e o problema da efetividade. In: CALGARO, Cleide; PEREIRA, Agostinho Oli Koppe; PEREIRA, Henrique Mioranza Koppe (Orgs.). Consumo, democracia e meio ambiente [recurso eletrônico]: Caxias do Sul, RS: Educs, 2016.

FROTA, Mário. União europeia quer acabar com a obsolescência programada, 2017. Disponível em: <http://www.netconsumo.com/2017/07/uniao-europeia-quer-acabarcom.html> Acesso em: 04 set. 2018.

GRAU, Eros Roberto. A ordem econômica na constituição de 1988. 13. ed. São Paulo: Malheiros. 2008.

HABERMAS, Jürgen. Consciência moral e agir comunicativo. Tradução Guido A. de Almeida. Rio de Janeiro: Tempo Brasileiro, 1989

O discurso filosófico da modernidade: doze lições. Tradução Luiz Sérgio

Repa, Rodinei Nascimento. São Paulo: Martins Fontes

HOCHSCHILD, Arlie Russell. The commercialization of intimate life: notes from home and workd. University of California Press. First Edition, 2003

JAMESON, Frederic. Pós-modernismo: a lógica cultural do capitalismo tardio. São Paulo: Ática, 1996.

LATOUCHE, Serge. Pequeno tratado do descrescimento sereno. São Paulo: Editora WMF Martins Fontes, 2009.

LEMOS, Patrícia Faga Iglecias. Resíduos sólidos e responsabilidade civil pós-consumo. 3. ed. São Paulo: RT, 2014

LEONARD, Annie. A história das coisas: da natureza ao lixo, o que acontece com tudo que consumimos. Rio de Janeiro: Zahar, 2011. p. 23.

LIPOVETSKY, Gilles. Os tempos hipermodernos. 4 ed. São Paulo: Editora Barcarolla, 2011. Letras, 2008.

O luxo eterno: da idade do sagrado ao tempo das marcas. São Paulo: Companhia das

A felicidade paradoxal: ensaios sobre a sociedade de hiperconsumo. Trad. Maria Lúcia Machado. São Paulo: Companhia das Letras, 2007. 
MAGERA, Márcia. Os caminhos do lixo: a obsolescência programada à logística reservada. Campinas: Editora Átomo, 2012.

MINISTÉRIO DA JUSTIÇA. Ministério da Justiça lança estudo sobre consumo consciente. 2013. Disponível em: <http://www.justica.gov.br/news/ministerio-da-justica-lanca-estudosobre-consumo-consciente> Acesso em: 04 set. 2018.

MIRAGEM, Bruno. Vício oculto, vida útil do produto e extensão da responsabilidade do fornecedor: comentários à decisão do REsp 984.106/SC, do STJ. Revista de Direito do Consumidor, São Paulo, v. 85, p. 325 et. seq., Jan. 2013

OLSSON, Giovanni. Relações internacionais e seus atores na era da globalização. Curitiba: Juruá, 2003.

ONU. Objetivo 12: Assegurar padrões de produção e de consumo sustentáveis. 2018. Disponível em: <https://nacoesunidas.org/pos2015/ods12/> Acesso em: 04 set. 2018.

ONU: Com mais de 1 bilhão de veículos, planeta precisa de modelo mais sustentável de transporte. 2015. Disponível em: <https://nacoesunidas.org/com-mais-de-1bilhao-de-veiculos-planeta-precisa-de-modelo-mais-sustentavel-de-transporte-afirma-onu/> Acesso em: 04 set. 2018.

PACKARD, Vance. A estratégia do desperdício. São Paulo: Ibrasa, 1965.

PEREIRA, Agostinho Oli Koppe; PEREIRA, Henrique Mioranza Koppe; PEREIRA, Mariana Mioranza Koppe. Hiperconsumo e ética ambiental. In: PEREIRA, Agostinho Oli Koppe; HORN, Luiz Fernando Del Rio (Orgs.). Relações de consumo: meio ambiente. Caxias do Sul, RS: Educs, 2009.

PEREIRA, Agostinho Oli Koppe; CALGARO, Cleide; PEREIRA. Desenvolvimento sustentável e o consumocentrismo: o paradoxo da modernidade. In: PEREIRA, Agostinho O. Koppe; CALGARO, Cleide; PEREIRA, Henrique M. Koppe (Orgs).. O consumo da sociedade moderna [recurso eletrônico]: consequências jurídicas e ambientais. Caxias do Sul, RS: Edusc, 2016.

RODRIGUES, Alexandre Lamas; PEREIRA, Agostinho Oli Koppe; CALGARO, Cleide. Uma análise do hiperconsumo moderno na sociedade de risco. In: CALGARO, Cleide; PEREIRA, Agostinho Oli Koppe; PEREIRA, Henrique Mioranza Koppe (Orgs). Consumo, democracia e meio ambiente [recurso eletrônico]: Caxias do Sul, RS: Educs, 2016.

RUIZ MALBAREZ, MC; ROMERO GONZÁLEZ, Z. La responsabilidad social empresarial y la obsolescencia programada. Saber, Ciencia y Libertas. 6, 1, 127-135, Jan. 2011.

SILVA, Rogerio da. A educação e a informação como meio de humanizar as relações de consumo. Revista Justiça do Direito, Passo Fundo, v. 1, n. 2, p. 96-08, jul./dez. 2011 
A concretização do direito fundamental de proteção ao consumidor/cidadão vulnerável: um debate acerca das intersecções público-privado em face da proposta de políticas públicas de autonomia dos Procons. 2016. 233 f. Tese (Doutorado em Demandas Sociais e Políticas Públicas). Programa de Pós-Graduação em Direito, Universidade de Santa Cruz do SUL - UNISC, Rio Grande do Sul.

STJ. Recurso Especial: 984.106 - SC (2007/0207915-3). Relator: Ministro Luis Felipe Salomão. DJ: 20/11/2012. Disponível em: $<$ https://ww2.stj.jus.br/processo/pesquisa/?num_registro=200702079153\&aplicacao=processo s.ea> Acesso em: 08 set. 2018.

TECHMUNDO. Apple diz que obsolescência programada é a "coisa mais louca do mundo". 2018. Disponível em: <https://www.tecmundo.com.br/mercado/131034-apple-dizobsolescencia-programada-coisa-louca-mundo.htm> Acesso em: 04 set. 2018.

TJRJ. Apelação Cível: 0006196-91.2008.8.19.0004. Relator: Des. Sérgio Jerônimo A. Silveira. $\quad$ DJ: 19/10/2011. Disponível em: <http://www1.tjrj.jus.br/gedcacheweb/default.aspx?UZIP=1\&GEDID=0003B8FADE5F6745 8E8CFE782FFCE2975F5E9AC403131449> Acesso em: 08 set. 2018. 